\title{
Evaluation of the Role of Cetyltrimethylammoniumbromide (CTAB) and Acetylenicglycol (AG) Admixture on Fly Ash Based Geopolymer
}

\author{
T. REVATHI ${ }^{1}$, R. JEYALAKSHMI ${ }^{1 *}$, \\ N. P RAJAMANE ${ }^{2}$ and M. SIVASAKTHI ${ }^{1}$ \\ 'Department of Chemistry, SRM University, Chennai, Tamil Nadu, India. \\ ${ }^{2}$ CACR, SRM University, Chennai, Tamil Nadu, India. \\ *Corresponding author mail: rajyashree64@gmail.com \\ http://dx.doi.org/10.13005/ojc/330225
}

(Received: April 28, 2016; Accepted: February 02, 2017)

\begin{abstract}
Alkali activation of fly ash with proper mix design and correct formulations can exhibit very good strength and chemical resistance and other potentially valuable characteristics similar or even better than conventional Portland cement. Utilization of fly ash activated system as binder material in construction industry can limit the consumption of virgin materials required for the production of cement as well less energy intensive process in the manufacturing stage leads to lower greenhouse gas emission. Goeopolymeric products with characteristic properties can be achieved on a laboratory scale level by optimizing the process conditions using selected source material with the addition of admixture. On contrary, Usage of variable source material in a large scale preparation, issues like flow ability, control of setting time are always present that need to be studied. This study was conducted on leaching of fly ash by hybrid activator solution namely sodium silicate, sodium hydroxide, for preparing geopolymer matrix wherein geopolymer (GPC) mortar was made with the addition of organic admixture Cetyltrimethylammonium bromide (CTAB), Acetylenic glycol (AG) as flow ability enhancer with dosage ranging from $0-2 \%$ by keeping the Liquid/Solid as 0.45 . The Compressive strength of the mortar in the order $30 \mathrm{Mpa}$ was achieved with good flow property by the addition acetylenic glycol and the zeta potential value was found to be similar in the order of control specimen(-15.4mv). Analysis of SEM microstructure of the matrix revealed that binding gel of type Na-S-H are found to be more on AEG added matrix than that of CTAB.
\end{abstract}

Keywords: fly ash, Geopolymer,compressive strength, slump, SEM/EDAX, Zeta potential.

\section{INTRODUCTION}

Geopolymer has recently emerged as a greener binder material for sustainable construction ${ }^{1}$. It is well known for its excellent properties such as fire and acid resistance, high compressive strength, low shrinkage and solidification of heavy metal wastes $^{2-5}$. Geopolymers are used in the toxic metal encapsulation and also used for the preparation of zeolite by incorporation of sodium hydroxide in the reactive system. ${ }^{6}$ It has tremendous potential applications of new areas in recent years ${ }^{7,8}$. One of 
the best ways is to synthesize, geopolymer a binder made by alkali-activated solution because of its low-cost, environment-friendly, energy-saving and resource-recycling benefits.

The alkali activation of aluminosilicate materials is a chemical process that transforms partially or wholly vitreous structures into compact cementitious skeletons. The key processes involved in the synthesis of geopolymers are: (a) Dissolution of fly ash or similar alumino-silicate precursors to provide the Aluminium and all or part of the Silicon constituents needed. (b) hydrolysis reaction to generate aluminum and silicate species and finally (c) condensation of these species and/or silicates from the activator to build up geopolymeric network structures. Geopolymers (GP) with frameworks of $\left[\mathrm{SiO}_{4}\right]^{4 "}$ and $\left[\mathrm{AlO}_{4}\right]^{5 " t e t r a h e d r a l ~ l i n k e d ~ a l t e r n a t e l y ~}$ by sharing all the oxygen atoms, are generally amorphous aluminosilicates or semi-crystalline zeolites depending on the alkaline activator used in their manufactures and reaction conditions. The negative charge of $\left[\mathrm{AlO}_{4}\right]^{5 "}$ tetrahedron on skeleton is balanced by extra-framework cations of $\mathrm{Na}^{+}, \mathrm{K}^{+}$and $\mathrm{Ca}^{2+}$ ions. ${ }^{9}$ Corresponding to different $\mathrm{Si} / \mathrm{Al}$ ratios, the geopolymers are composed of network structures made up of polysialate (-O - Si- O- $\mathrm{Al}-\mathrm{O})$, polysialate siloxo (-O- Si- O - $\mathrm{Al}-\mathrm{O}-\mathrm{Si}-\mathrm{O}-$ ), and polysialate disiloxo (- O -Si- O- Al- O -Si- O -Si- O).

The interaction of various process parameters, nature of admixtures on the compressive strength and workability of Geopolymer products are complex and hence final Geopolymer products exhibit different performance properties viz. high compressive strength, high thermal resistance, low shrinkage \& low thermal conductivity, high level of resistance to a range of different acids and salt solutions etc. It is also important to note that all Geopolymer products will result all of these properties or in other words, no single formulation matrix posses all the properties. Hence formulations recipes are required to tailor made Geopolymer mixes to attain the required specifications and technical performance. This will be possible only with thorough understanding of the raw material reactivity, chemistry, role of admixtures and reaction conditions.

The commercial superplasticizers viz., lignosulphonate, sulphonate naphthalene formaldehyde (SNF), sulphonate melamine formaldehyde (SMF), and polycarboxylates which are used in the production of concrete that cement particles by electrostatic repulsion through adsorption process, enhance workability, giving high performance and improve durability. The mechanism and working nature of superplasticizers in OPC have been well reported in literature. ${ }^{10-14}$. Such type of chemical admixtures does not work in Geopolymer system because of high alkaline conditions. ${ }^{15-20}$

Flyash activated with $85 \%$ of $12.5 \mathrm{M} \mathrm{NaOH}$ solution and $15 \%$ of waterglass with commercial chemical admixtures such as lignosulphonates, melamines(first and second generation products) and polycarboxylates (latestgeneration) were reported. The flow table spread results showedthat the polycarboxylates admixture gave the highest spread, AAFA without admixture came in the second place, melamines admixturecame in the third place, whilst lignosulphates admixturecame in the last place. Studies using commercial superplasticizers such as Sika Viscocrete-3430 (CONPLAST SP-430), showed that these high range water reducers had negative on the compressive strength of Fly ash based geopolymer but improved workability of the concrete. ${ }^{21-22}$

The effect of third generation SP such as vinyl copolymers, poly acrylate copolymers along with modified form of melamine, naphthalene, Polycarboxylate ester based, on alkali activated slag and fly ash based geopolymers have been

Table.1: Chemical composition of low lime fly ash (Indian)

\begin{tabular}{lllllllll}
\hline Chemical & $\mathrm{SiO}_{2}$ & $\mathrm{Al}_{2} \mathrm{O}_{3}$ & $\mathrm{CaO}$ & $\mathrm{Fe}_{2} \mathrm{O}_{3}$ & $\mathrm{~K}_{2} \mathrm{O}$ & $\mathrm{MgO}$ & $\mathrm{Na}_{2} \mathrm{O}$ \\
\hline $\begin{array}{l}\text { Component } \\
\text { (wt \%) of fly }\end{array}$ & 47.55 & 33.45 & 2.099 & 10.17 & 1.65 & 0.005 & 0.015 \\
\hline
\end{tabular}


reported. ${ }^{23}$ It was found that addition of $\mathrm{N}$-based SP improved the workability upto $2 \%$ mass of binder without affecting the strength. Studies on evaluation of PC based SP on fly ash Geopolymer showed appreciable reduction in the strength around 20 to $35 \%$ with reference to original concrete. Similar such conditions are existing for geopolymer from slag and fly ash base combination. Reports on the addition of fly ash with slag improving workability of alkali activated slag system. ${ }^{24,25}$ On the contrary report on Indian fly ash did not improve the workability even at $40 \%$ fly and $60 \%$ slag base.

Till date suitable admixture not deleterious for compressive strength, working under high alkaline conditions has not been reported in literature and further research in this area is necessary in order to scale up the Geopolymer products.

The present study aims to investigate the suitability of organic compounds CTAB and AG working under $\mathrm{NaOH}$ and sodium silicate combined activated fly ash Geopolymer system.

\section{MATERIALS AND METHODS}

\section{Physico-chemical properties of fly ash}

The class F fly ash (Indian) are characterized with regard to their mineralogy, microstructure and morphology. The chemical composition of the low

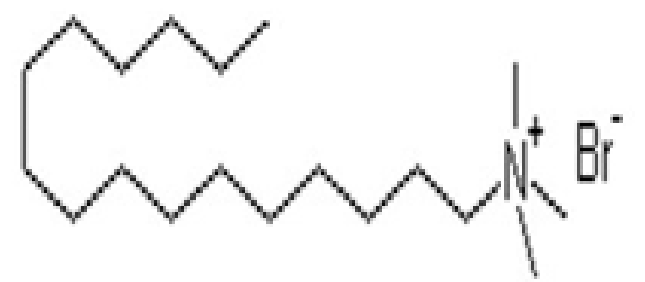

Fig.1(a): Molecular structure of CTAB<smiles>CC(C)CC(C)(O)C#CC(C)(O)CC(C)C</smiles>

Fig.1(b): Molecular structure of AG lime fly ash is determined by X-ray Fluorescence (XRF) analysis and is summarized in Table1. XRD (Siemens D 501 diffractometer using Cu K_ radiation) diffractogram. The microstructure of the source material (Fly ash) and Geopolymer mix were taken using Scanning Electron Microscope.

The chemical composition of fly ash(Indian) as determined by XRF are according to ASTM C 618. The silica/alumina ratio of the fly ash by mass was $\left(\mathrm{SiO}_{2} / \mathrm{Al}_{2} \mathrm{O}_{3}\right) 1.42$.

\section{Alkali activator}

A mixture of sodium hydroxide $(\mathrm{NaOH})$ and sodium silicate $\left(\mathrm{Na}_{2} \mathrm{SiO}_{3}\right)$ solutions was used as the activator solution. The concentration of sodium hydroxide solution was kept constant (12 M) for all mixtures. Sodium silicate solution used in the present study contains mass ratio of $\mathrm{Si}_{2} \mathrm{O} / \mathrm{Al}_{2} \mathrm{O}_{3}$ as 0.5 with chemical compositions $30.7 \% \mathrm{SiO}_{2}, 11.4 \%$ $\mathrm{Na}_{2} \mathrm{O}$ and $57.9 \%$ water. The fine aggregate used was natural sand having a nominal maximum size of $1.18 \mathrm{~mm}$. The activator solutions of desired quantity were prepared a day before and used with other ingredients to enhance reactivity of the solution.

\section{Organic admixture}

The SP used in this study was cetyltrimethyl ammonium bromide (CTAB) and Acetylenic glycol (AG). CTAB (Chemie Pvt. Ltd., Mumbai), a cationic surfactant having chemical formula $\mathrm{C}_{19} \mathrm{H}_{42} \mathrm{BrN}$. This was chosen due to its relative inertness with calcium or sodium ions present in system. The molecular structures of CTAB, AG based SP are shown in Fig.1 (a) \& (b). Acetylenic glycol(AG) a nonionic surfactant with a bilateral-symmetrical structure and an acetylene bond at the center of its molecule. Its hydrophobic nature lower the surface tension thereby significant reduction of water sensitivity is expected. 20

\section{Geopolymer mix design}

Geopolymeric paste and mortar mixtures were proportioned to study the effect of SP dosage. The mixture proportions of paste and mortar are presented in Table 2. The total binder content was constant and constituted one fourth of the total mixture. The mix proportions of the pastes were similar to those of the mortar mixtures with the aggregates excluded. 


\section{Mixing, casting and curing}

Fine and coarse aggregates prepared in saturated surface dry condition and the binders (fly ash) were dry mixed thoroughly in the mixing pan for 2 minutes. The premixed alkaline activator solution was then added gradually in to the mixer. Mixing was continued for further $3 \mathrm{~min}$. SP's dosage was varied from $0.5 \%, 1 \%, 1.5 \%, 2.0 \%$ by mass of fly ash and the whole mix was blended for $4 \mathrm{~min}$. to eliminate the clustering of fine particle.

The geopolymer mortars were prepared to obtain a uniform mortar mixture. Cylindrical moulds, $75 \mathrm{~mm}$ in diameter and $150 \mathrm{~mm}$ in height, were filled with geopolymer mortar in two layers and compacted on a vibrating table. Cube samples (25x 25x 25 $\mathrm{mm}^{3}$ ) were casted with geopolymer paste. All the

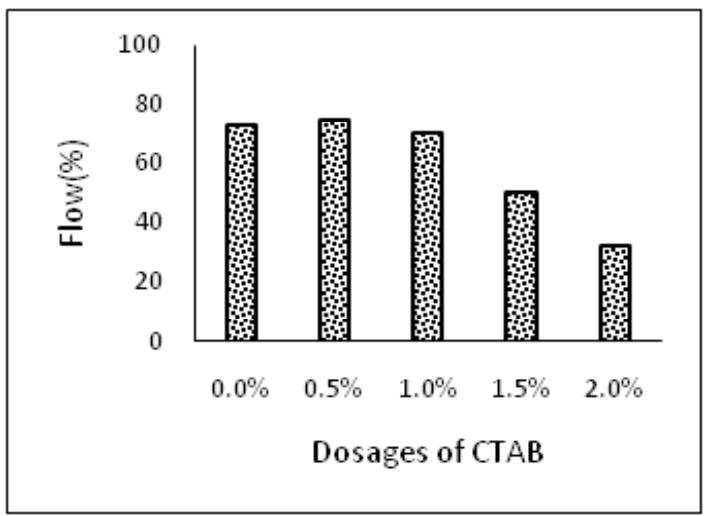

specimens were sealed with polythene sheets to prevent excess evaporation/loss of moisture. After $24 \mathrm{~h}$ of curing, specimens were oven dried for 24 $\mathrm{h}$ at $70^{\circ} \mathrm{C}$ and then demolded.

\section{Test methodology}

The workability of fresh geopolymer concrete mixtures were tested by Slump test following ASTM: C1437.Flow of fresh geopolymer mortars were measured in accordance with ASTM C143707 to determine workability loss of fresh concretes. A layer of the fresh concrete mix about was poured into the truncated conical mould (top diameter $=100$ $\mathrm{mm}$, bottom diameter $=200 \mathrm{~mm}$, height $=300 \mathrm{~mm}$ ) and tampered 25 times with tamper. The mould was firmly held against its base during the test or foot-rest brazed to the mould. Immediately after filling, the

Fig.2 (a) \& (b): Flow and compressive strength of geopolymer with different dosages of CTAB

Table 2: Geopolymer mix design

\begin{tabular}{|c|c|c|c|c|c|c|c|c|c|c|}
\hline \multirow{2}{*}{$\begin{array}{l}\text { S. } \\
\text { no }\end{array}$} & \multirow{2}{*}{ Designation } & \multicolumn{6}{|c|}{ Mortar mixture quantity $\left(\mathrm{Kg} / \mathrm{m}^{3}\right)$} & \multicolumn{3}{|c|}{ Activator solution } \\
\hline & & FA & Sand & SP & $\begin{array}{c}\text { Sodium } \\
\text { hydroxide }\end{array}$ & $\begin{array}{l}\text { Sodium } \\
\text { silicate }\end{array}$ & L/S & $\begin{array}{l}\mathrm{Na}_{2} \mathrm{O} \\
/ \mathrm{Al}_{2} \mathrm{O}_{3}\end{array}$ & $\begin{array}{c}\mathrm{H}_{2} \mathrm{O} \\
/ \mathrm{Na}_{2} \mathrm{O}\end{array}$ & $\begin{array}{r}\mathrm{Si}_{2} \mathrm{O} \\
\mid \mathrm{Al}_{2} \mathrm{O}_{3}\end{array}$ \\
\hline 1 & AD-O & 500 & 1000 & 0.0 & 350 & 100 & 0.5 & 0.43 & 3.35 & 0.5 \\
\hline 2 & $A D-C-1$ & 500 & 1000 & 2.5 & 350 & 100 & 0.5 & 0.43 & 3.35 & 0.5 \\
\hline 3 & AD-C-2 & 500 & 1000 & 5 & 350 & 100 & 0.5 & 0.43 & 3.35 & 0.5 \\
\hline 4 & AD-C-3 & 500 & 1000 & 7.5 & 350 & 100 & 0.5 & 0.43 & 3.35 & 0.5 \\
\hline 5 & AD-C-4 & 500 & 1000 & 10 & 350 & 100 & 0.5 & 0.43 & 3.35 & 0.5 \\
\hline 6 & $A D-A-5$ & 500 & 1000 & 2.5 & 350 & 100 & 0.5 & 0.43 & 3.35 & 0.5 \\
\hline 7 & $A D-A-6$ & 500 & 1000 & 5 & 350 & 100 & 0.5 & 0.43 & 3.35 & 0.5 \\
\hline 8 & AD-A-7 & $/ / 500$ & 1000 & 7.5 & 350 & 100 & 0.5 & 0.43 & 3.35 & 0.5 \\
\hline 9 & AD-A-8 & 500 & 1000 & 10 & 350 & 100 & 0.5 & 0.43 & 3.35 & 0.5 \\
\hline
\end{tabular}


cone was slowly lifted and the unsupported concrete was then slumped. The decrease in the height of the concrete was then measured. The consistency of the mixes was measured using a Vicat needle as described in ASTM C191-08. Values of penetration distances were measured within $5 \mathrm{~min}$. after the preparation of the paste. The test was conducted in room temperature.
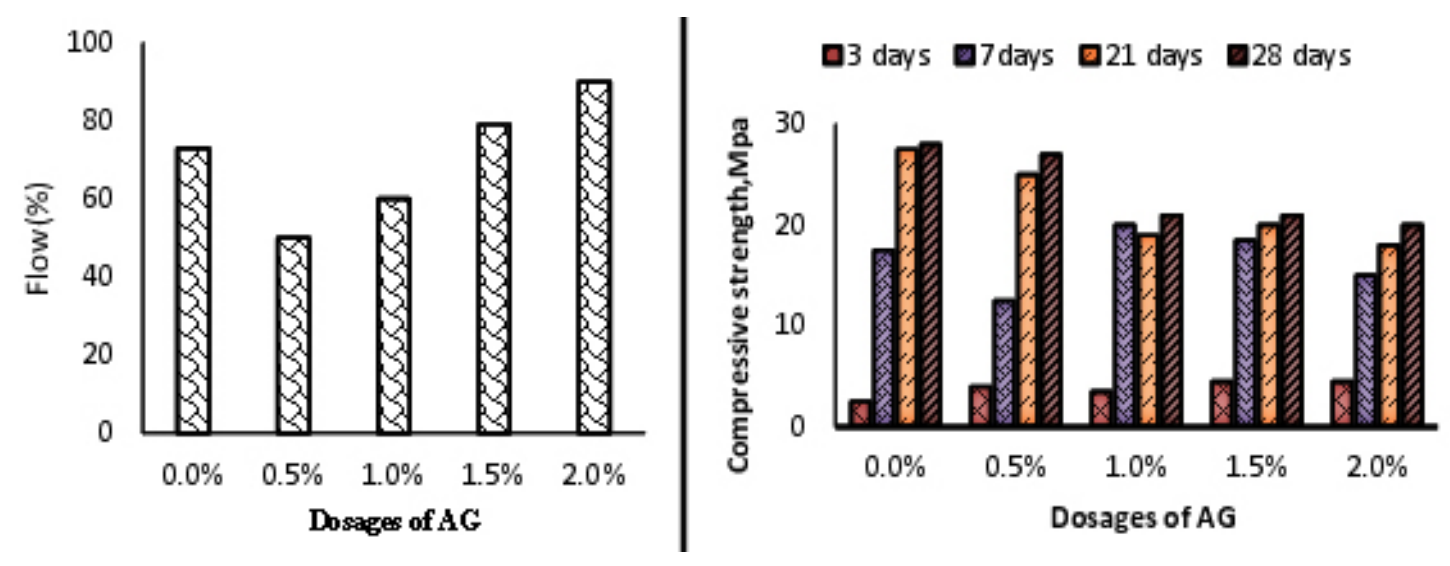

Fig.3 (a) \& (b): Flow and compressive strength of geopolymer with different dosages of $A G$

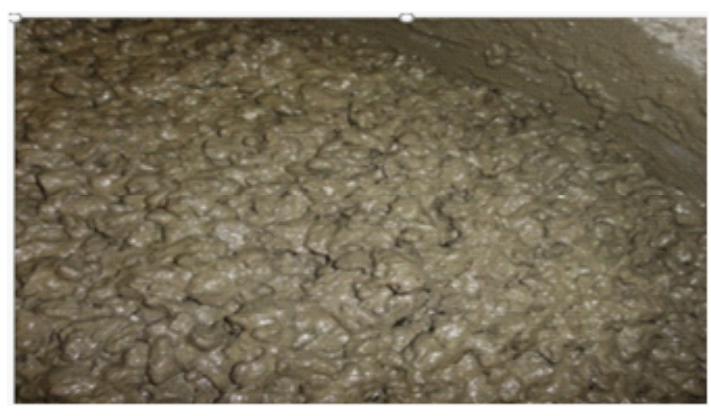

(a) Addition of CTAB to GP concrete

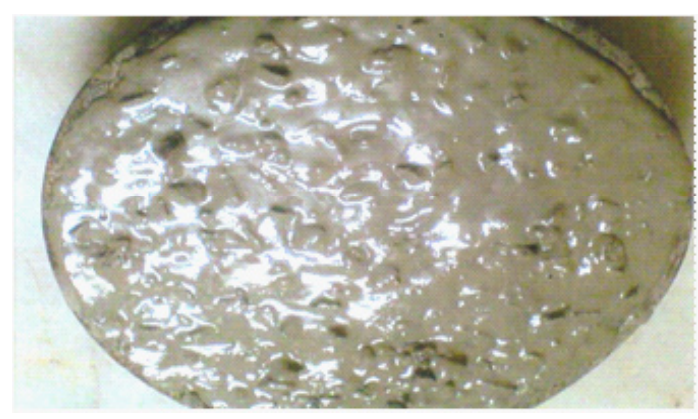

(b) Addition of AG to GP concrete

Fig.4: Fresh geopolymer concrete with the addition of (a)CTAB (b) AG

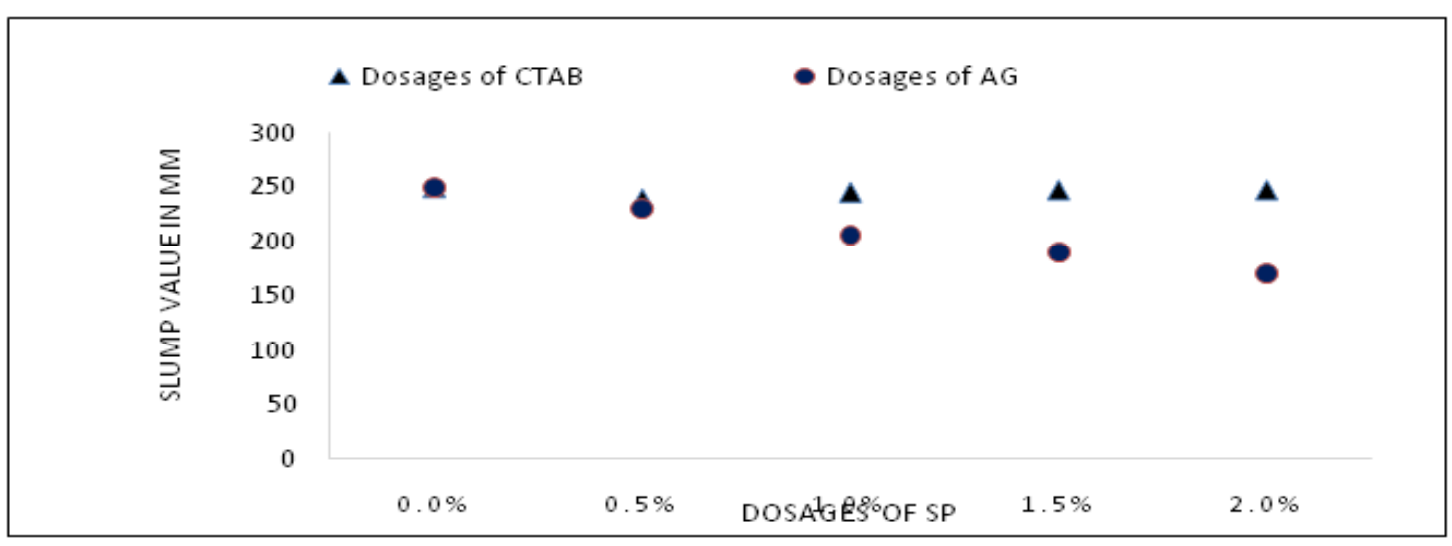

Fig.5: Slump value of geopolymer with varying concentration of CTAB and AG. 
Compressive strength test was conducted at different curing regimes 3,7 and 28 days, with a loading rate of $0.33 \mathrm{MP}$ a/s in a Controls CTM machine. Average of 3 test results was taken for calculations. Malvern Zetasizer (Nano series) was used to measure the zeta potential against the standard potassium tungsto -silicate solution and calculations were made through Zetasizer software. 0.5 weight $\%$ of Geopolymer matrices in deionized water was used to measure the zeta potential.

\section{RESULTS and DISCUSSIONS}

X-ray diffractogram analysis has shown that the fly ash consists of approximately $70 \%$ amorphous materials and remaining mineral phases like quartz, magnetite, anhydrite, anorthite, hematite, and other minerals. Amorphous content in the fly ash are easily dissolve during the initial step of the geopolymerisation process, yielding higher amounts of reactive $\mathrm{SiO}_{2}$ and $\mathrm{Al}_{2} \mathrm{O}_{3}$ to combine during the agglomerate phase of the geopolymeric reaction. This increases the rate of geopolymerization, thereby giving high compressive strength.

\section{Flow and strength of GP mixes}

The effect of addition of SP on flow of fresh GP mixes of liquid/solid $=0.45$ having $12 \mathrm{M}$ of $\mathrm{NaOH}$, have been studied and was presented in the Figure (2) \& (3). The flow of alkali-activated fly ash concrete with the addition of CTAB decreased with increasing dosage level. The mixes were found to be very stiff. In the case of AG, fresh mix showed slight enhancement in the flow make it more workable even in the reduced water content. The flow and compressive strength data on various curing time with and without addition of SP is shown in the Fig 2(a) \& 2(b). and Fig 3(a) \&3(b)

It was found that addition of CTAB has not improved the flowability beyond $0.5 \%$ and reduction in the compressive strength was found to

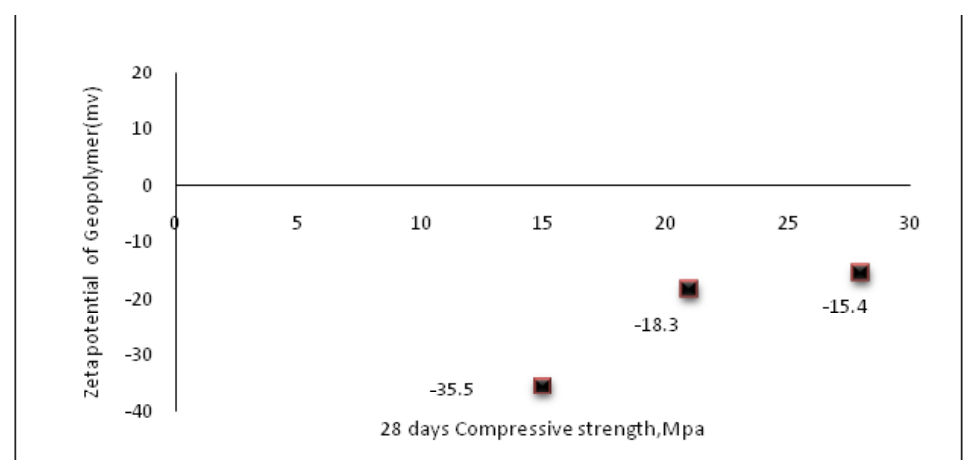

Fig. 6: Zeta potential and compressive strength Geopolymer
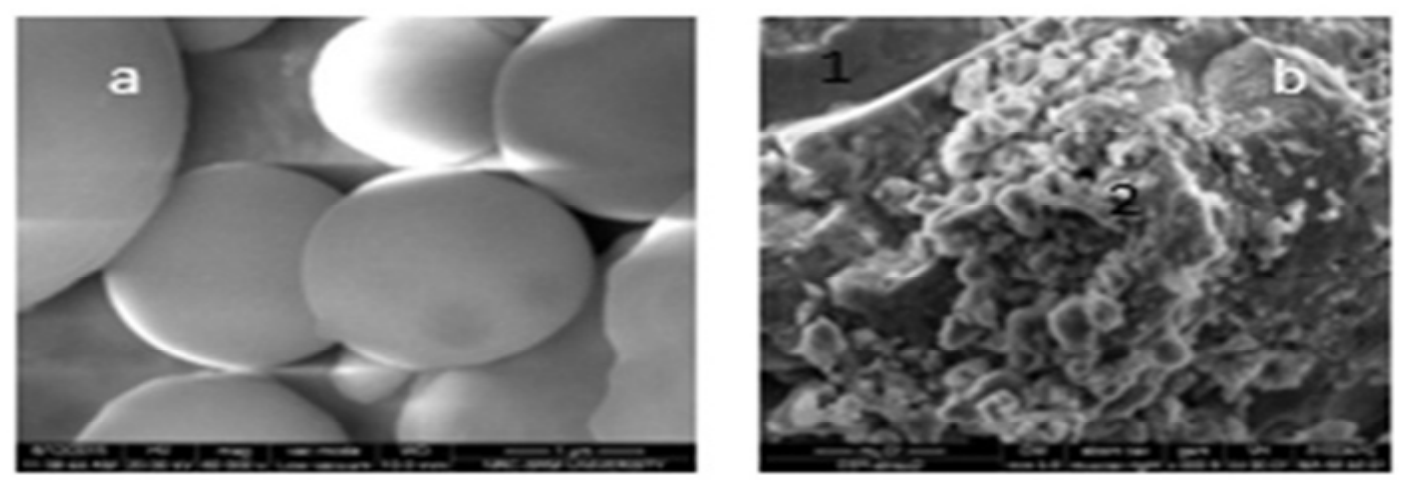

Fig. 7: SEM images of (a)original fly ash and (b) geopolymer without SP 


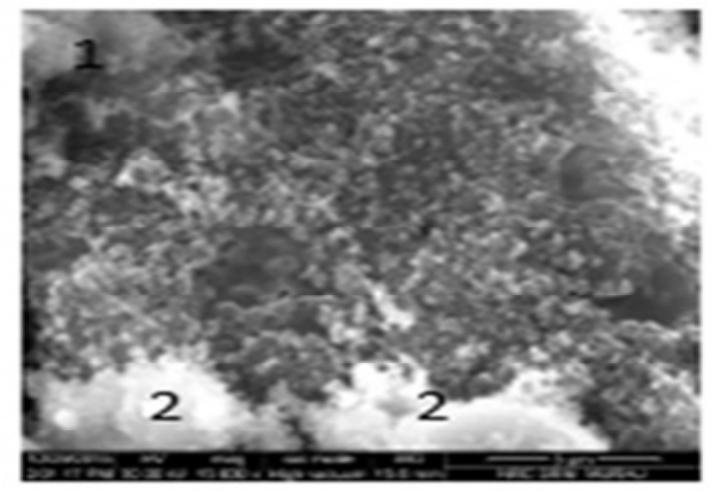

1.Geopolymer

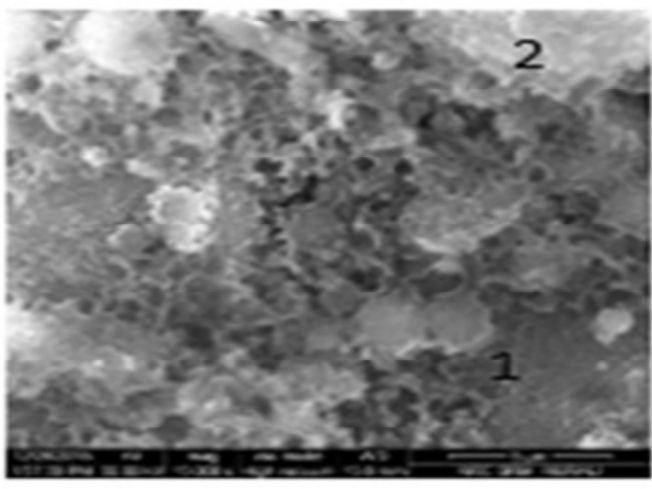

2. Gel formation over the fly ash

Fig. 8: SEM images of geopolymer with the addition of (a) AG and (b) CTAB
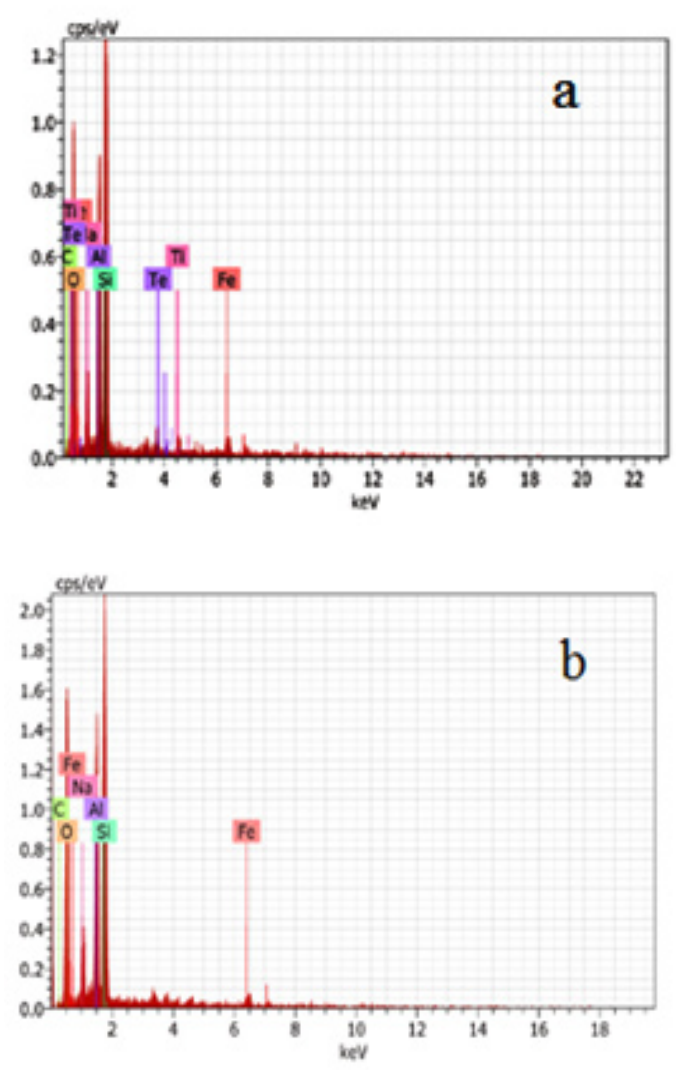

Fig. 9: EDAX for GP mortar with the addition of (a)CTAB (b) AG

be in the order of $35 \%$. In the case of AG-mixes, the compressive strength has not altered much in all the curing regime as well dosage upto $2 \%$.

\section{Slump test}

The fresh fly ash based geopolymer has shown in Fig.4(a) \& 4(b). Variations of slump values of the mixes by the addition of SP are shown in the Fig.5. Variation of workability is not so significant in the case of CTAB where as the slump values decreased from $250 \mathrm{~mm}$ to $130 . \mathrm{mm}$ when AG dosage increased from 0.00 to $2 \%$. Water retarding nature AG may assist the setting property of fresh Geopolymer concrete.

\section{Zeta potential}

The Geopolymer strength characteristics especially Fly ash base depend on the nature of surface charges over the reactive component generally amorphous/glassy content. During the alkali activation, surface layer of the fly ash particles gets deprotonated forming soluble form of $\mathrm{SiO}_{2}$ species.

Normally surface layer fly ash particles contain a significant amount of readily leachable elements mostly anionic groups being silicates [-O-SiO ${ }^{2-}$ ] and aluminates [-O-AIO]. Zeta potential value of fly ashes is in the range of -20 to $-25 \mathrm{mv}$. In our present study the fly ash precursor showed the negative value of $-27.8 \mathrm{mv}$.

During the geopolymersiation reaction, activator solution having $\mathrm{OH}^{-}$ions react with the aluminate species on the surface of fly ash forming $\left[\mathrm{Al}(\mathrm{OH})_{4}\right]$ and with silicate species form either $\left[\mathrm{SiO}(\mathrm{OH})_{3}\right]$ or $\left[\mathrm{SiO}_{2}(\mathrm{OH})_{2}\right]^{2-}$, thereby establishment 
of negatively charged double layer. Further $\mathrm{Na}+$ ions of the alkaline activator react to form a sodium alumino silicate gel layer, $\left[\mathrm{Na}_{z}\left(\mathrm{AlO}_{2}\right)_{x}\left(\mathrm{SiO}_{2}\right)_{y} \cdot \mathrm{nNaOH}\right.$. $\mathrm{mH}_{2} \mathrm{O}$ ], on their surfaces. ${ }^{26}$ This reaction step is very important to achieve desirable mechanical strength. While forming Na-Al-Si-H gel the accumulation of more $\mathrm{Na}^{+}$ions in the double layer decrease the zeta potential.

In the present study also the same trend was observed showing smaller negative value for zeta potential, (-15.4mv proved that combined activator solution (Sodium hydroxide and Sodium silicate) helped for agglomeration of fly ash particles to facilitate the geopolymersiation reaction. The effect of addition of SP on zeta potential studied under the same conditions of that of the control. The charge distributed over the surface of the SP disturbing the agglomeration of fly ash with activator during the Geopolymeriasation. This was reflected in the zeta potential value measured CTAB admixed Geopolymer paste(-35.5mV) as shown in Fig.6. It may be due to the adsorption of cationic CTAB. In the case of $A G$, a nonionic compound, shifting the more positive value than that of CTAB but it was lower than that of control. The extent of reaction with the presence of SP is found to be low in all these studies and it was found to be reflected in the compressive strength data.

\section{SEM images}

The morphology of fly ash precursors observed from SEM photograph showed that fly ash particles are appeared to be hollow, spherical as thin walled hollow sphere Fig 7(a) \& (b). SEM picture of alkali activated fly ash mortar after 28 days of curing time clearly showed that dense microstructure by the formation gel binder. The compacted structure of mortar this study indicated that large amount of reactive product without any crack corresponding to mechanical compressive strength. The addition of SP in the mortar does not affect the microstructure of the Geopolymer formed as shown in Fig 8(a) \& (b).
The gel formation over the surface of fly ash particles are clearly seen.

EDAX of specific sample area is shown in Fig.9 Average ratio of Si/Al for fly ash geopolymer was approximately 1.5 was maintained.The data were obtained from the average of five sample areas. The measured $\mathrm{Na}$ atomic weights of $12 \mathrm{M} \mathrm{NaOH}$ mortar of 0.67-0.9.

\section{CONCLUSION}

Short term engineering properties like consistency and flowability of fly ash based geopolymer using organic admixture such as Cetyltrimethylammoniumbromide, acetylenic glycol will help us to find out the time available for placing,compaction and transport of Geopolymer during large scale preparation. The workability of GP concrete was found to be improved than that control while addition AG from 0.5 to $2 \%$. The compressive strength of heat cured $\left(80^{\circ} \mathrm{C}\right)$ specimens were not much affected by AG addition whereas around $35 \%$ reduction were found in $C T A B$ at all dosage compared to that of control specimens. The results from EDAX indicate that major components in Geopolymer were silicon and aluminum having $\mathrm{Si} /$ Al ratio 1.5 with small amount of sodium.

The shift in value of zeta potential to more positive with and without addition of SP in fly ashwater slurry revealed that addition of SP facilitate the dispersion of fly ash particles. The value of zeta potential observed in the case of geopolymer mortar with addition of SP were found to be more or less same to control specimens which indicates the gel formation has not much affected. Therefore, further collaborative research is required to develop suitable admixture to efficient the geopolymer technology.

\section{ACKNOWLEDGMENT}

The authors are grateful for financial support from the DST, GOI.

\section{REFERENCES}

1. Joseph Davidovits, Geopolymer Chemistry and Applications: $3^{\text {rd }}$ edition Geopolymer institute, 2008.

2. Fernandez.A- Jimenez A.Paloma, Criado.M 
Microstructure development of alkali activated cements descriptive model ,Cem .Conc. Res,2005,35,1204-1209.

3. Duxson.P, Fernandez-Jimenez.A, ProvisJ.L., LukeyG.C., PalomoA.,van DeventerJ.S.J., Geopolymer technology: the current state of the art, Journal of Materials Science,2007, 42 (9), 2917-2933.

4. RajamaneDr.N.P., NatarajonM.C. and JeyalakshmiR., Pozzalonic indusrial waste based geopolymer concretes with low carbon footprints, ICI Journal, Special issue: Future Cement,2015,(385), 22-38

5. Swane poel J.C and strydom C.A. utilization of Fly ash in a geopolymeric material, Journal ofApplied Geochemistry ,2003,17,11431148

6. Nasser Y. Mostaf, Rasha A. Garib, Z. K. Heiba, Omar H. Abd-Elkader, M. M. AlMajthoub,Synthesis of pure zeolite P2 from calcium silicate hydrate; tobermorite, Orient J Chem, 2015,(2),3

7. Blissett, R. S., \& Rowson, N. A, A review of the multi-component utilization of coal fly ash. Fuel, 2012, 97, 1-23.

8. Shrray Srivastava1, Ravindra Gadhave, Recent developments in Inorganic polymers: A Review with focus on Si-Al based inorganic polymers, Orient J Chem,2015,(4),31

9. Joseph Davidovitts, J.Duxson, P., FernandezJimenez, A., Provis, J. L., Luke , Geopolymers: Inorganic polymeric new materials. Journal of Thermal Analysis, 1991,37,1633-1656.

10. Hanehara S, Yamada K. Interaction between cement and chemical admixture from the point of cement hydration, absorption behaviour of admixture, and paste rheology. Cem Concr Res 1999,29(8),1159-65.

11. Brooks J, Johari M, Mazloom M. Effect of admixtures on the setting times of highstrength concrete. Cem Concr Compos 2000,22(4),293-301.

12. Puertas F, Vázquez T. Early hydration cement. Effect of admixtures superplasticizers. Mater de Constr,2001,51(262),53-61.

13. Chandra S, Björnström J. Influence of cement and superplasticizers type and dosage on the fluidity of cement mortars-Part I. Cem Concr
Res 2002,32(10),1605-11.

14. Chandra S, Björnström J. Influence of superplasticizer type and dosage on the slump loss of Portland cement mortars-part II. Cem Concr Res 2002,32(10),1613-9.

15. Bakharev T, Sanjayan J, Cheng Y-B. Effect of admixtures on properties of alkali activated slag concrete. Cem Concr Res 2000,30(9),1367-74.

16. Palacios M, Puertas F. Effect of superplasticizer and shrinkage-reducing admixtures on alkaliactivated slag pastes and mortars. Cem Concr Res 2005,35(7),1358-67.

17. Puertas F, Palomo A, Fernández-Jiménez A, Izquierdo J, Granizo M. Effect of superplasticisers on the behaviour and properties of alkaline cements. Adv Cem Res 2003,15(1),23-8.

18. Criado $M$, Palomo $A$, Fernández-Jiménez A, Banfill P. Alkali activated fly ash: effect of admixtures on paste rheology. Rheol Acta 2009,48(4),447-55.

19. Wallah EE, Rangan BV. Low calcium fly ash based geopolymer concrete: longterm properties. Research report GC2, Perth: Faculty of Engineering, CurtinUniversity of Technology, 2003

20. Montes Carlos, Zang Di, Allouche Erez N. Rheological behaviour of fly ashgeopolymers

with the addition of superplasticizers. J Sust Cem-Based Mater 2012,1,179-85.

21. Nuruddin M, Fadhil, Demie Samuel, Fareed $\mathrm{M}$, Shafiq Nasir. Effect ofsuperplasticizer and $\mathrm{NaOH}$ molarity on workability, compressive strengthand microstructure properties of selfcompacting geopolymer concrete. World Acad Sci, Eng Technol ,2011,51,907-14.

22. Reddy B Siva Konda, Varaprasad J, Reddy K Naveen Kumar. Strength andworkability of low fly-ash based geopolymer concrete. Ind J Sci Technol2010,3(12),1188-9.

23. Talling B, Brandstetr J. Present state and future of alkali-activated slagconcretes. In: 3rd Int. Con. on fly-ash, silica fume, slag and natural pozzolanasin concrete, Norway, vol. 2, SP 114-74; 1989,1519-46.

24. Wang Shao-Dong, Scrivener Karen L, 
Pratt PL. Factors affecting the strength of alkali-activated slag. Cem Concr Res, 1994,24(6),1033-43.

25. Parameswaran PS, Chatterjee AK. Alkali activation of Indian blast furnace slags. In: 8th In. Concr. Chem. Cem., Rio de Janeiro, 1986, vol 4, 86-91.
26. Chamila Gunasekara, David W. Law , Sujeeva Setunge , Jay G. Sanjayan Chamila Gunasekara, David W. Law, Sujeeva Setunge, Jay G. Sanjayan, Zeta potential, gel formation and compressive strength of low calciumfly ash geopolymers, Construction and Building Materials ,2015,95,592-599 